Research Article

\title{
Exploration on Mechanical Behaviours of Hyacinth Fibre Particles Reinforced Polymer Matrix-Based Hybrid Composites for Electronic Applications
}

\author{
Pradeep Kumar Panda, ${ }^{1}$ J. Jebastine, ${ }^{2}$ Madhialagan Ramarao, ${ }^{3}$ Shaik Fairooz, ${ }^{4}$ \\ Chirra Kesava Reddy, ${ }^{5}$ Omaima Nasif, ${ }^{6}$ Saleh Alfarraj, ${ }^{7}$ Velu Manikandan, ${ }^{8}$ and I. Jenish $\left({ }^{9}\right.$ \\ ${ }^{1}$ Department of Packaging, Yonsei University, Wonju-Si 26493, Gangwon-Do, Republic of Korea \\ ${ }^{2}$ Department of Electronics and Communication Engineering, Jeppiaar Engineering College, Chennai 641407, Tamil Nadu, India \\ ${ }^{3}$ Department of Mechanical Engineering, Bharath Institute of Higher Education and Research, Chennai 641407, \\ Tamil Nadu, India \\ ${ }^{4}$ Department of Electronics and Communication Engineering, Malla Reddy Engineering College, Secunderabad 500100, \\ Telangana, India \\ ${ }^{5}$ Department of Mechanical Engineering, Lincoln University College, Petaling Jaya, Selangor, Malaysia \\ ${ }^{6}$ Department of Physiology, College of Medicine and King Khalid University Hospital, King Saud University, Medical City, \\ P.O. Box-2925, Riyadh 11461, Saudi Arabia \\ ${ }^{7}$ Zoology Department, College of Science King Saud University, Riyadh 11451, Saudi Arabia \\ ${ }^{8}$ College of Environmental \& Bioresource Sciences, Chonbuk National University, Iksan 570752, Republic of Korea \\ ${ }^{9}$ Department of Mechanics, Seenu Atoll School, Hulhumeedhoo, Addu City 19060, Maldives
}

Correspondence should be addressed to I. Jenish; jenish@satollschool.edu.mv

Received 16 August 2021; Accepted 25 October 2021; Published 6 December 2021

Academic Editor: P Ganeshan

Copyright ( 2021 Pradeep Kumar Panda et al. This is an open access article distributed under the Creative Commons Attribution License, which permits unrestricted use, distribution, and reproduction in any medium, provided the original work is properly cited.

\begin{abstract}
Biocomposites with polylactic acid (PLA), nanosilica parts, and water hyacinth fibres have been developed in this experimental study. By changing the weight percentage of nanosilica particulate matter $(0,2,4,6$, and 8 percent) with PLA and water hyacinth fibres, five composite mates were produced through a double screw extruder and compression moulding machine. According to the ASTM standards, the process to machine, the composite specimens have been adopted from the water jet machining process. The tensile, compression, flexural, impact, hardness, and water absorption tests were performed on the composite specimens to assess various mechanical properties and absorbance behaviour. The test findings reveal the significant improvement in the tensile and flexural properties of the composites. Composites contain 6 percent of the fine nanosilica particles by weight. Concerning adding the growing weight percentage (4 percent) of nanosilica particles to the composites, the water absorption properties of the composites have significantly improved. The tensile strength of $6 \%$ nanosilica mixed specimens showed the highest tensile stress rate as $36.93 \mathrm{MPa}$; the value was nearly $3.5 \%$ higher than the $4 \%$ nanosilica mixed composite specimens.
\end{abstract}

\section{Introduction}

Researchers have become particularly concerned with reducing their use of synthetic plastics because of environmental problems caused by plastic waste, not biodegradable. Synthetic mixing with biological (hybrid) materials and using fully biodegradable materials have been included in recent innovations. Bioplastics have been developing in the last ten years to replace synthetic plastics [1]. In most modern engineering fields, composites' most advanced physical features are more used against conventional metallic and alloying materials. Despite the high technical and physical features of the alloys, scientists are still trying to detect the new composite material due to its high strength to 
rigidity ratio, resistance to corrosion, and cost factors. Consistent positive deterministic factors have also been found in the enhanced polymer materials (FRPs) [2], such as low weight, high stiffness-to-weight ratios, good chemical resistance, and corrosion resistance. Generally polymer matrix composites are widely used in aerospace, automobile, and electronic applications. The manufacture of printed circuit boards (PCBs) reached an all-time high of $\$ 51$ billion in 2009, thanks to the rising demand for electronic devices. However, the PCB industry's rapid growth encourages it to focus on circuit innovation rather than the environmental impact of the materials used. It is necessary to take a fresh approach to the creation of more environmentally friendly foundation materials. Most commercial PCB materials are glass fibre cloth reinforced epoxy composites because they provide a suitable combination of mechanical and electrical qualities. Figure 1 reveals the schematic diagram of printed circuit boards.

Figure 2 reveals the types of fibre. Water hyacinth is a possible source of low-cost, nontoxic, and abundant natural fibre in Indonesia. The fibre content is comparable to that from other sources [3] and has approximately 40\% cellulose content. The content of cellulose has a considerable impact on biocomposite properties. Like the previous study [4, 5], the high content of cellulose leads to better mechanical and thermal properties. The commonly used natural fibres are microfibers of a diameter of $1-1000 \mu \mathrm{m}$ (micron metre) or nanofibers of a diameter of 1-100 nanometres [6, 7]. In previous research studies, microfibers from kenaf [8], water hyacinth $[9,10]$, ramie $[11,12]$, vacuous palm oil bunches [13], and microalgae's [14] were used. However, when dispersed in a stretch matrix, these microfibers usually form agglomerations or porosities, which produce low mechanical characteristics. Fibre must be nanosized to reduce agglomeration. Due to the high contact surface area, lower density, and good mechanical properties, smaller fibres result in better biocomposites $[6,15,16]$. Different cheap filler materials have been attempted in conjunction with these to reduce the cost to the total composite output to increase the strength of the FRPs. In most research publications $[17,18]$, silica has played a role in this sequence of filler materials such as calcium carbonate. A novel approach was to produce tough epoxy resin made from rice husk with a particle size distribution of $40-80 \mathrm{~nm}$ [19]. This study will discuss the Charpy impact comportment of composites based on WH fibre. This research shows that the impact strength of polymer composites is based on WH fibre compounds. It is sufficiently competitive compared to other composites based on natural fibre [20]. There was an increase in the tensile characteristics, impact strength, and fatigue life of reinforced glass-fiber composites by adding silica nanoparticles to the contents [21]. The incorporation of silica particles reveals a beneficial effect on the elasticity module, flexural modulus, and hardness of $2 \mathrm{wt} \%$ threshold value. However, silica's tensile and bending strength are reduced by a slightly higher bending strength than their tensile parts [22]. Increased interfacial bonding for Basalt fibre reinforced epoxy composite is added by adding $\mathrm{SiO} 2$ nanoparticles to the fibre surface [23]. Epoxy/silica/kenaf composites with different concentrations have been manufactured with silica particles. Untreated kenaf fibres with modified silica epoxy composites have increased their flexural and impact strength [24]. Aquatic plants like water hyacinth (Eichhornia crassipes) have a rapid growth rate, making them undesirable as garden plants. Water hyacinth's rapid growth has led to low levels of dissolved oxygen in the water, and it can spread across large areas. Water hyacinth is not all bad. It absorbs heavy metals and provides livestock feed, and its fibre can be used to make handicrafts $[25,26]$. It is found that for water hyacinth-polypropylene composites, except traction strength, all mechanical properties are improved adequately. In the course of this study, water hyacinth fibre was chosen as a refurbishment, and nanosilica particles were chosen as the filler materials for polylactic acid (PLA). The execution methodology of this experimental research work is shown in Figure 3.

\section{Materials and Methods}

Matrix material, one of the reinforcement materials which is used in this experimental work, i.e., polylactic acid (PLA) and nanosilica powder, was purchased from Covai Seenu and Company Ltd, Coimbatore, Tamil Nadu, India. The green unit Coimbatore, Tamil Nadu, India, provides further reinforcing material, i.e., water hyacinth fibres. The nanoparticles known as silicon dioxide, also known as nanosilicas, are the base of a large degree of biomedical research due to their stability, low toxicity, and ability to operate with multiple molecules and polymers. Nanoparticles of silicon dioxide appear in white powder form. The physical properties of these nanoparticles are provided in the table below. Table 1 shows the various basic physical, chemical, and thermal properties of nanoparticles with silicon dioxide. P1 consists of pure PLA particulates of $100 \mathrm{wt}$ percent. P2 is made of $80 \mathrm{wt} \%$ pure PLA particles, $0 \mathrm{wt} \%$ silica powder, and 20 wt $\%$ water hyacinth fibre. P3 contains 80 percent wt of pure PLA particles and 20 percent wt of powder of silica and 0 percent wt of powder of water hyacinth. P4 consists of $80 \%$ by weight of PLA pure, $2 \%$ by weight of silicon powder, and $18 \%$ by weight of hyacinth powder. P5 consists of pure PLA particles of $80 \% \mathrm{wt}$, silicone powder of $4 \% \mathrm{wt}$, and water hyacinth powder of $16 \%$ wt. P6 includes $80 \%$ wt of pure PLA, $60 \%$ wt of silica powder, and $14 \%$ wt of powder of hyacinth water. P7 comprises $80 \mathrm{wt} \%$ of the pure part of PLA, eight wt $\%$ of the silica, and $128 \mathrm{wt} \%$ of the water powder hyacinth.

The particle size of silica obtained at first does not match the size required. To comply with the requirement, silica powder was processed in a ball mill. The measured nanosilica particle diameter in the range of 75 to $100 \mathrm{~nm}$ was used as a reinforcement content. Before feeding these mixtures into the double screw extruder machine, PLA particles were heated above the melting temperature. Following heating, the PLA particles were transformed into a liquid stage. The weight percent of enhancement materials, i.e., nanosilica powder and short water hyacinth fibres, was added to liquid state PLA. After 45 minutes of adding filler and refill material to the fluid state PLA matrix, the entire mixture was thoroughly misled in one blender. The composite mix of the 


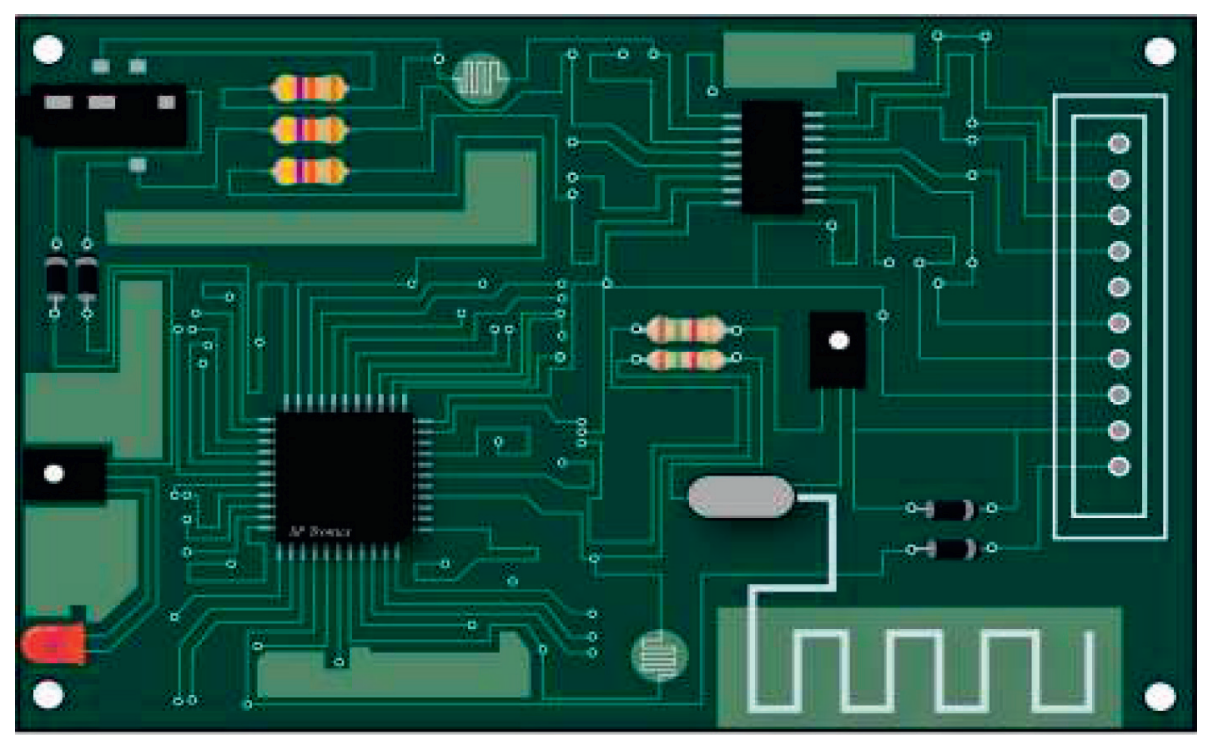

FIGURE 1: Schematic diagram of printed circuit boards.

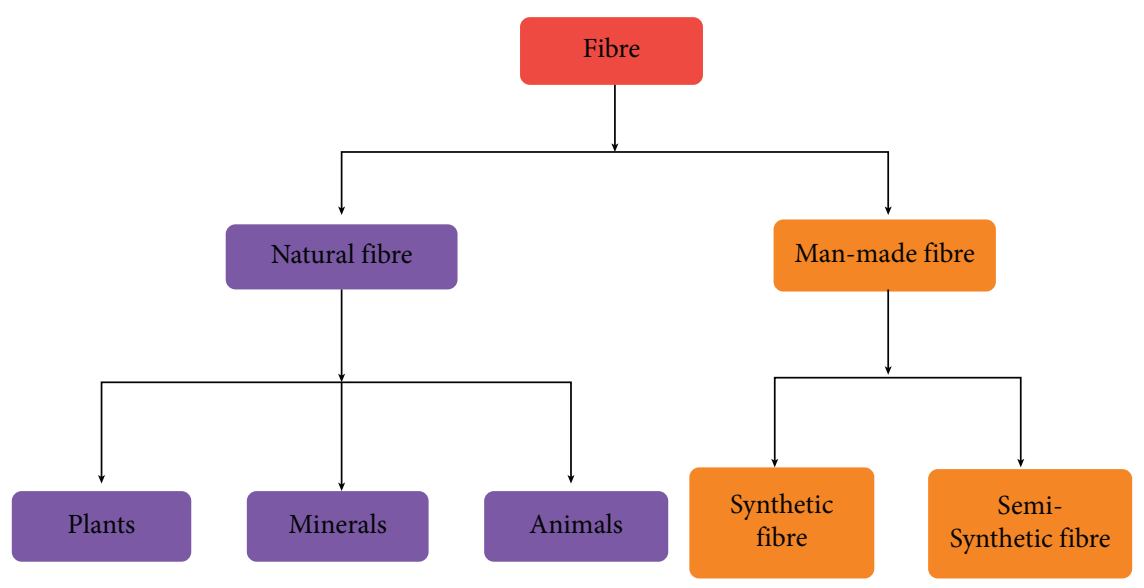

Figure 2: Types of fibre.

array and the reinforcing and the filler materials of smaller pieces $(3 \mathrm{~cm}$ to $5 \mathrm{~cm}$ ) in length was prepared by a double screw extruder. Figure 4 reveals the double screw extrusion process arrangement.

The composition of the rectangular bars from wellprepared, hybrid-based composite parts was prepared by a hydraulic injection moulding machine. The combined water hyacinth fibre, PLA, and silica particles had allowed the compression moulding machine to heat up to $100{ }^{\circ} \mathrm{C}$ at a specific hydraulic pressure for up to thirty minutes. The required composite plates had been collected and cooled at room temperature after the processing time of 30 minutes. Figure 5 reveals the advantages of injection moulding.

The composite plates were transferred after the cooling process to the water jet machining process, and the necessary composite components were separated from the composite compound according to ASTM standards. For the remaining compositions, the same process was repeated. Figure 6 reveals the tensile test sample. Tensile, flexural, and impact tests for establishing the mechanical properties of composites were permitted for the well-prepared composite specimens. The tensile test (ASTMD638), compression test (ASTM-D695 M), and flexural test (ASTMD790-10) of the composites at a load rating of $1 \mathrm{~mm} / \mathrm{min}$ were used with a computerised $400 \mathrm{kN}$ universal testing machine. Figure 7 reveals the universal testing machine. A Charpy impact test was also performed on the composite impact test specimens in the Impact Testing machine as defined by the ASTM D6110-97 standards. Figure 8 reveals the Impact Testing machine. A water absorption test was also performed in composite specimens of the water absorption test, according to the ASTM D5229 pure water standards. The tensile, compressive, bending, impact, toughness, and water absorption tests were given in different sample dimensions as given in Table 2.

The results of mechanical and water absorption tests, such as ultimate tensile strength, flexural strength, flexural strength, impact strength, and water absorption percentage, have been shown in the results and the discussions as a graphical colour plot. 

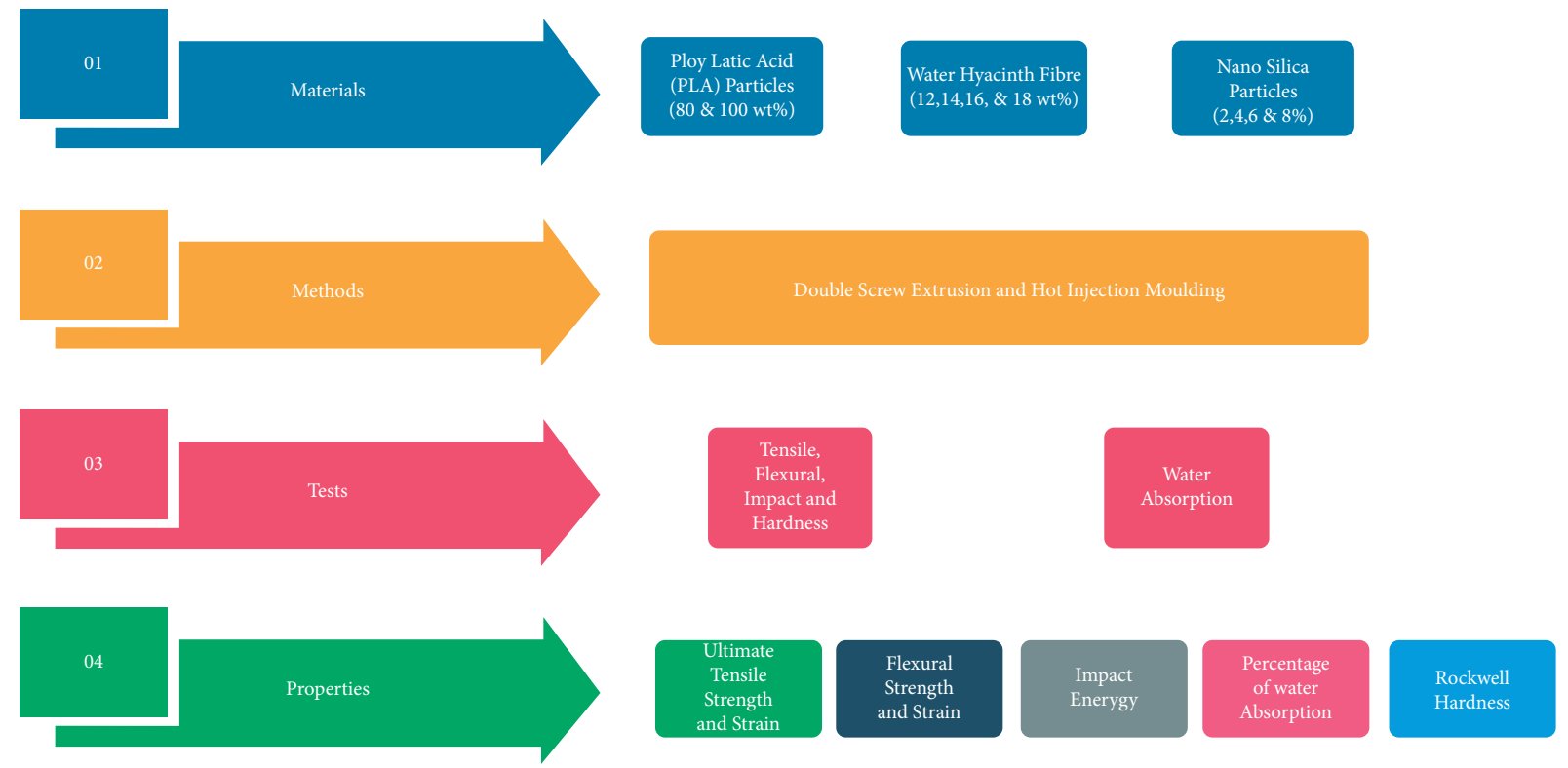

FIGURE 3: Execution methodology of this experimental research work.

TABle 1: Physical, chemical, and thermal properties of silica.

\begin{tabular}{lc}
\hline Chemical composition & Silica $46.83 \%$ and oxygen $53.33 \%$ \\
\hline Density & $2.4 \mathrm{~g} / \mathrm{cm}^{3}$ \\
Molar mass & $59.96 \mathrm{~g} / \mathrm{mol}$ \\
Melting point & $1600^{\circ} \mathrm{C}$ \\
Boling point & $2230^{\circ} \mathrm{C}$ \\
\hline
\end{tabular}

\section{Results and Discussions}

3.1. Tensile Test. Figure 9 illustrates the tensile strength and tensile behaviour of the water hyacinth reinforced PLA-filled particulate composites containing different ratios of loaded nanosilica and water hyacinth. Without any water hyacinth fibre or nanosilicone (P1 composite), the pure PLA composite showed a tensile strength of $31.45 \mathrm{MPa}$ and the corresponding tensile strain rate was 0.34 percent. During the test, both ends were very strongly fixed on the grips of the universal test machine and the fracture test was performed with the gradual load at the speed of the crosshead to about $1 \mathrm{~mm} / \mathrm{min}$. The PLA matrix with $20 \mathrm{wt} \%$ nanosilica and $0 \mathrm{wt}$ $\%$ water-enhanced fibre composite (P2 composites) had a tensile strength value of $32.95 \mathrm{MPa}$, and the respective stress rate was $0.35 \%$. With a tensile strength value of $33.68 \mathrm{MPa}$ and a tensile pressure rate of 0.36 percent, the PLA matrix with $0 \mathrm{wt}$ percent nanosilica particles and $20 \mathrm{wt}$ percent hyacinth water fibre enhanced composites ( $\mathrm{P} 3$ composites).

After the test, the specimen was broken down at specimen length, and the fibre-pull-out fracture initially burns the load by fibre when it exceeds its load capacity, when the load was transferred to the matrix with the loss of interfacial strength from fibre to the matrix, thus losing the power interface between the fibre and the matrix. The addition of composites of 2 percent nanosilica particles ( $\mathrm{P} 4$ composites) showed the tensile strength of $34.93 \mathrm{MPa}$; the tensile strength of the $\mathrm{P} 1, \mathrm{P} 2$, and $\mathrm{P} 3$ composites is almost 3.7, 6.09, and 11.06 percent higher. Its corresponding pressure rate was 0.32 percent higher than $\mathrm{P} 1, \mathrm{P} 2$, and $\mathrm{P} 3$ composites. The mixed specimens (P5 composites) of $4 \%$ nanosilica particles had shown a tensile stress value of $35.67 \mathrm{MPa}$, nearly $2.11 \%$ higher than the mixed specimens of $2 \%$ nanosilica (P4 composites). The tensile strength of $6 \%$ nanosilica mixed specimens (P6 composites) showed the highest tensile stress rate as $36.93 \mathrm{MPa}$; the value was nearly $3.5 \%$ higher than the $4 \%$ nanosilica mixed specimens (P5 composites), and the tensile pressure rate was $0.37 \%$. The tensile strength of the $8 \%$ mixed specimens of nanosilica particles (P7 composites) has shown the stress value as $34.61 \mathrm{MPa}$; this value was almost $6.28 \%$ less than the $6 \%$ mixed particulate matter (P6 composites) for nanosilica, and the corresponding tensile strain rate was $0.35 \%$. In addition, the $6 \%$ nanosilica particles, which had $14 \%$ water hyacinth in PLA composite samples, showed the highest pressure value for a tensile of $36.93 \mathrm{MPa}$, which was almost 12.07 higher than their corresponding strain rate which was respected to $0.39 \%$. Similarly, given the tensile stress value of $4 \%$, the jacinth was as high as the other five combinations, with the exception of P6 composite specimens. It is much higher than the other five. The combined or mixed cumulative tensile strength was also $36.30 \mathrm{MPa}$ of $4 \%$ nanosilica particles and $6 \%$ water hyacinths higher. The respective strain rate was $0.38 \%$, which was equally higher than all mixed proportions. Compared to the pure PLA composites, this experiment demonstrates the greater strength of the particulate composite. The stress rate also decreases in the case of the particulate addition to the matrix material. The stiffness increases so that the value of the tensile strength rises substantially.

3.2. Flexural Test. Figure 10 shows the flexural strength conduct of water hyacinth fibre reinforced PLA filling composites of nanosilica particles and water fibre loaded. First, the specimen was placed over two supports in the standard fixture 


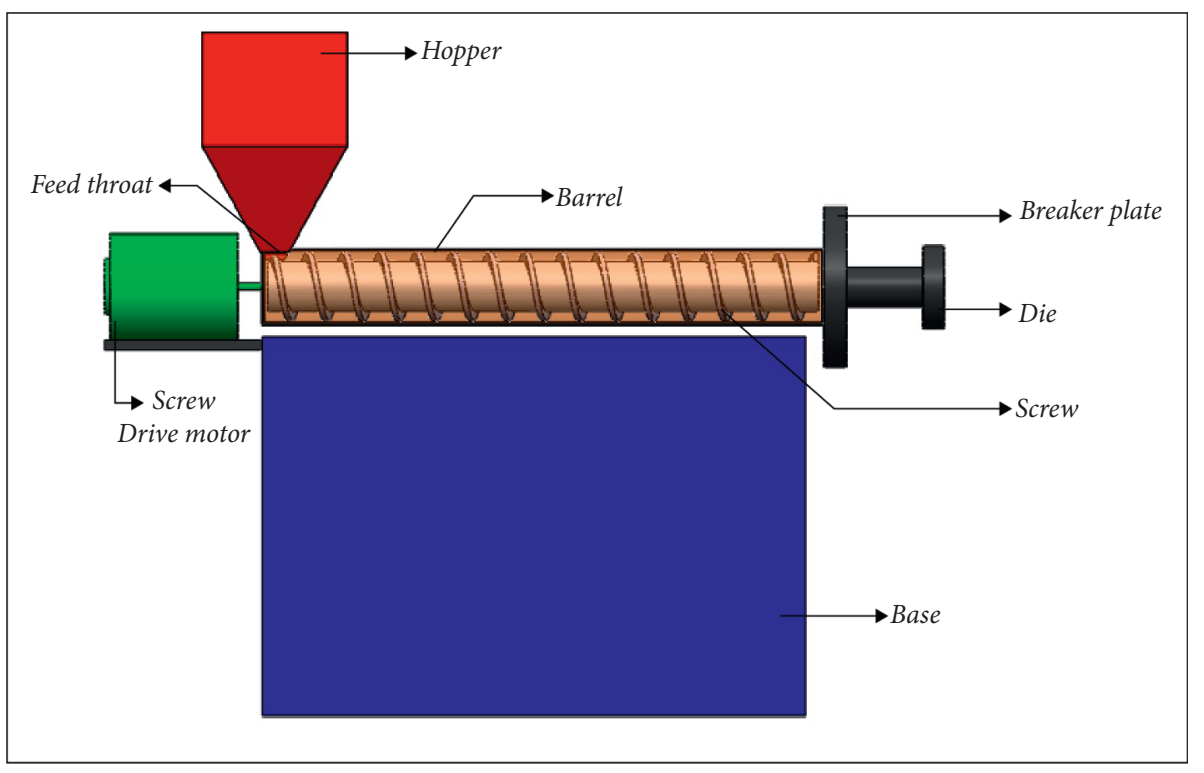

FIgURE 4: Double screw extrusion process arrangement.

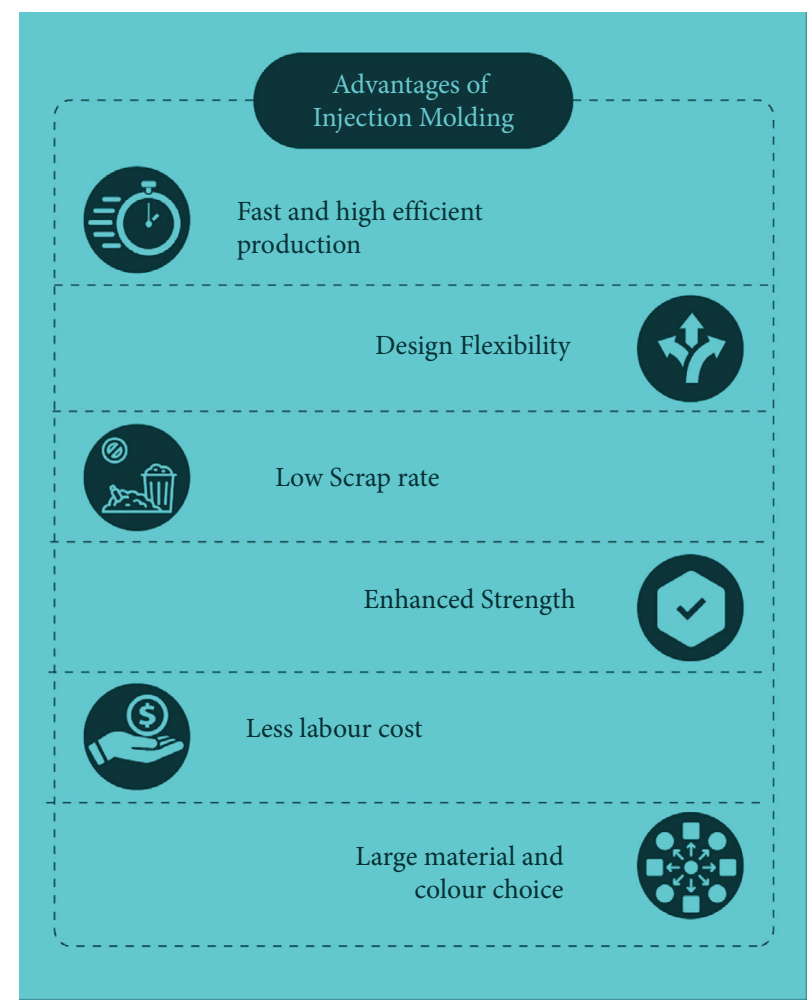

FIGURE 5: Advantages of injection moulding.

indicated by the standards. Then, using the universal test machine with standard crosshead speed, the centre of the specimen is permitted with the gradual load. With the aid of a digital device and a UTM device, the fracture load was noted.

As mentioned in the tensile strength analysis, the flexural strain value of $27.12 \mathrm{MPa}$ for PLA pure composites (P1 composite) with a strain rate of 4.9 percent was given in bending strength. With a bending value of $26.72 \mathrm{MPa}$, the PLA matrix with $20 \mathrm{~W} / 12 \%$ nanosilk particles and $0 \mathrm{~W} / 8 \%$ water hyacinth fibre reinforced composites had a bending strength value of 4.3\%. The PLA matrix had a flexural strength value of 28.97 $\mathrm{MPa}$. The appropriate stress rate was distinguished by 3.2 percent, with 0 wt percent nanosilk particles and 20 wt percent water hyacinth fibre reinforced composite (P3 composites). The added 2 percent of nanosilica particles ( $\mathrm{P} 4$ composites) showed that they have a Flexural Resistance value of $30.42 \mathrm{MPa}$; that value was nearly $12.17,13.85$, and 5 percent higher than the composites $\mathrm{P} 1, \mathrm{P} 2$, and $\mathrm{P} 3$, and their associated strain rate is 4.4 


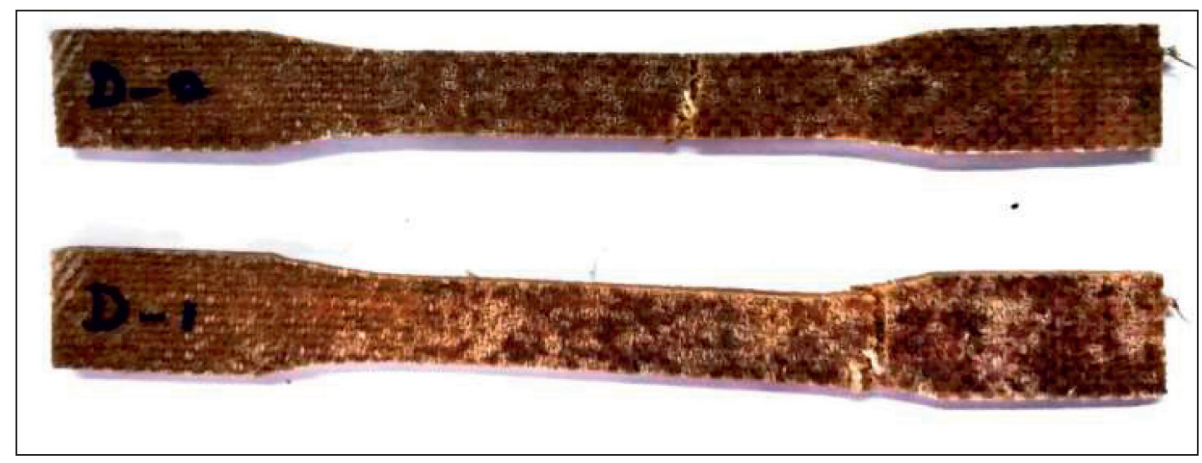

Figure 6: Tensile test sample.

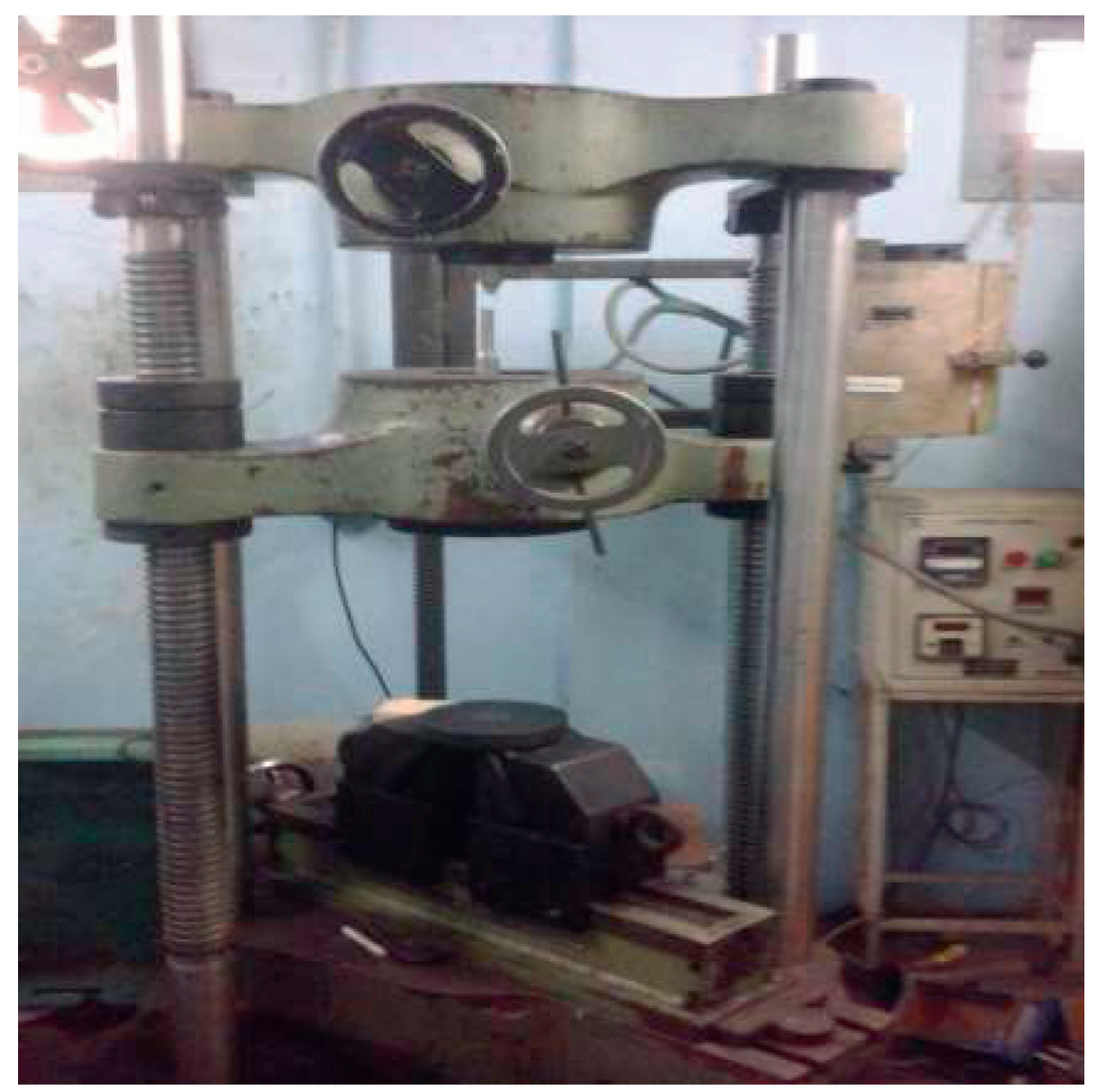

FIgURE 7: universal testing machine.

percent, with a lower rate than the originally clean specimens. The loaded 4 percent (P5 composites) of nanosilica particles also showed a value of $31.82 \mathrm{MPa}$. That value was significantly higher than the remaining 4,6 percent set of values. The highest flexural strength was $32.53 \mathrm{MPa}$ for 6 percent nanosilica particles (P6 composites) and was almost 19.95, 21.75, 12.30, and 6.98 and 2.23 percent above composites P2, P3, P4, and P5 and its corresponding strain rate is 5.3 percent. The $8 \%$ nanosilica composite (P7 composites) nanoparticles have shown a bending strength of $30.11 \mathrm{MPa}$, a value that was almost $7.44 \%$ lower than the P6 composites, and their corresponding stress rate was $4.7 \%$. The values observed were $30.42,31.82,32.53$, and $30.11 \mathrm{MPa}$ for the $18,16,14$, and 12 wt percent loaded water hyacinth as the value in nanosilica composites also demonstrated the spike in flexural stress. Whereas the $6 \%$ nanosilica particles and $14 \%$ hyacinths showed a tremendous increase in bending stress, the observed value is $32,53 \mathrm{MPa}$ with a strain rate of $5.3 \%$. All the observed results have demonstrated that the added particulate matter into the composites significantly increases the flexural stress value. Secondly, incorporating water hyacinth fibres maintains a higher bending strength while adding nanosilica particles to the matrix ( $6 \%$ nanosilica particles), reducing bending stress, and adding hyacinth again (14\%) increase strength and further reduce bending stress appropriately. 


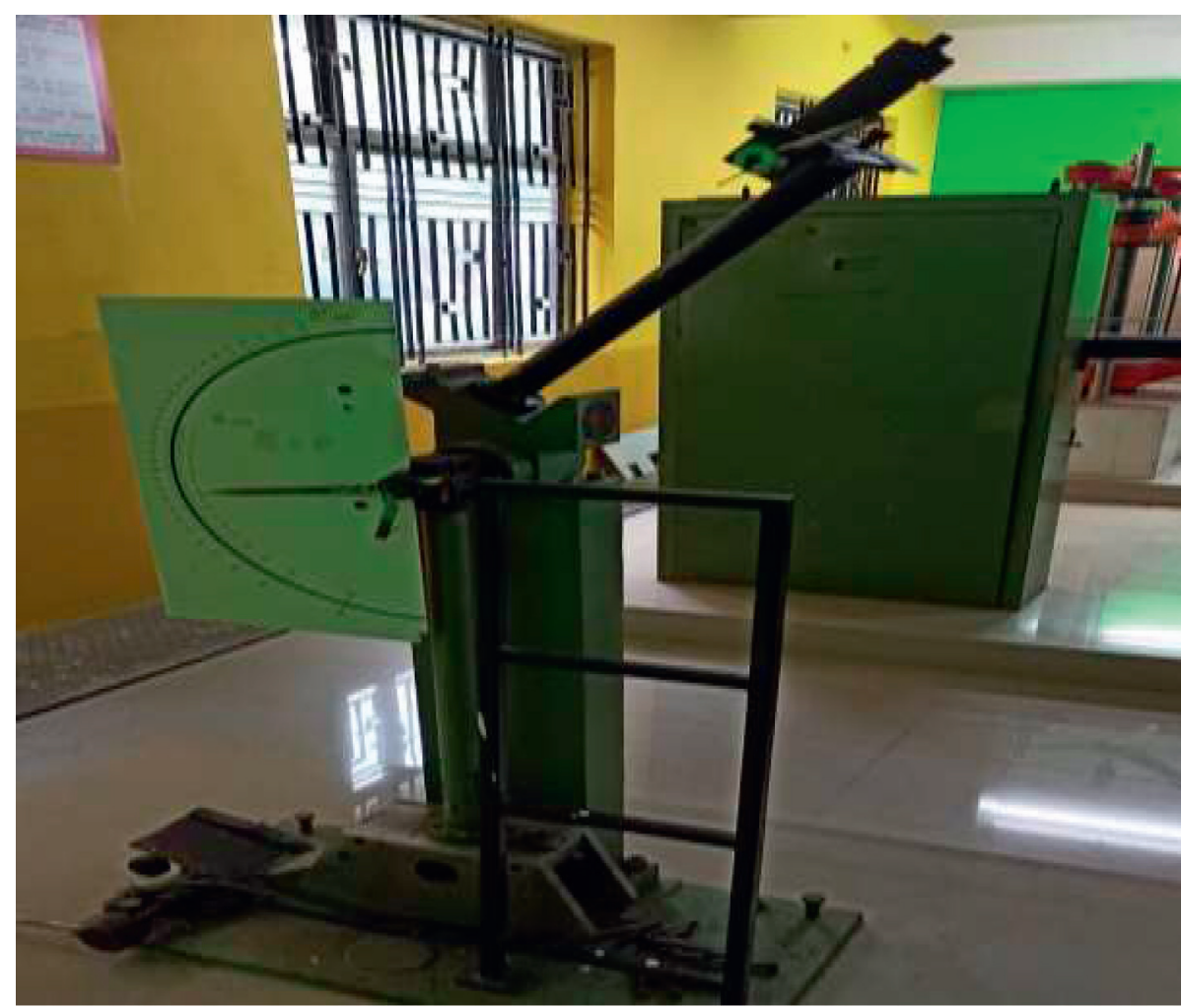

FIgURE 8: Impact Testing machine.

TABle 2: Composite specimen dimensions for mechanical and water absorption test.

\begin{tabular}{lc}
\hline Test & Dimensions in mm (length-width-thickness) \\
\hline Tensile & $165 \times 12 \times 5$ \\
Compressive & $150 \times 12 \times 5$ \\
Flexural & $100 \times 12 \times 5$ \\
Impact & $80 \times 12 \times 5$ \\
Water absorption & $100 \times 100 \times 5$ \\
\hline
\end{tabular}

\section{Charpy}

4.1. Impact Test. The impact strength of composites examined by the Charpy impact test is shown in Figure 11. The results demonstrated an additional 160.39, 46.21, 64.95, 24.77, and 10.88 percent in composites P2, P3, P4, and P5, respectively, and 6 wt percent of nanosilica particles in the composite P6. This is due to the fillers used by silica particles, which strengthened the PLA matrix less than $56 \mathrm{~nm}$ in the particle stage. The microparticle fillers (silica particles) helped increase the surface-to-volume ratio by providing a larger surface area. Thus, the stress transfer between the filler matrix was increased. In addition, the fillers showed good interfacial adhesion in the polymer matrix, which helped to increase stress transfer between the filler and the matrix.

Composite P6, compared with P1 composite ES, had a higher impact strength due to the presence of water hyacinth fibre and nanosilica particles that allowed greater power absorption in the event of an impact. Made of water hyacinth and nano silica are composites P4, P5, P6, and P7. The results enhance the impact strength of PLA from P4 to
P6 composites. Compared to all other composites, pure PLA (P1 composites) also provided a small impact strength (P2 to P7). The highest impact strength of composite P6 was $9.27 \mathrm{~kJ} / \mathrm{m} 2$, improving by $160.4 \%$ compared to pure PLA, because the water hyacinth and nanosilica continuous fibre provide additional energy absorption at impact. However, with the performance of the composite P2, impact to composites P3 to P7 was the lowest. The lack of water hyacinth fibre probably resulted. The result agreed with the finding from earlier studies of the subsequently reduced interaction among the fibres and the matrix by the formation of a crack and byproducts resulting from the reaction of nanosilica particles. Finally, because of the absence of reinforcement and filling materials in the PLA matrix, the impact properties of the composite material were reduced.

4.2. Rockwell Hardness. Hardness is a feature that measures the surface indentation and abrasion resistance of the material. Hardness is also a critical parameter that indicates the composite's durability and life span. The hardness of the various composition composites and PLA composite specimens is shown in Figure 12. All the composites produced were highly harder than the clean epoxy. This increased hardness was associated with the high rigidity and hardness of the distended stage parts, which can be reinforced due to their load carrying capacity. The results indicate that adding $6 \mathrm{wt} \%$ of nanosilica particles in the P6 composite improves hardness by $55.88,43.24,51.43,17.78$, and 8.16 percent, in P1, P2, P3, P4, and P5. 


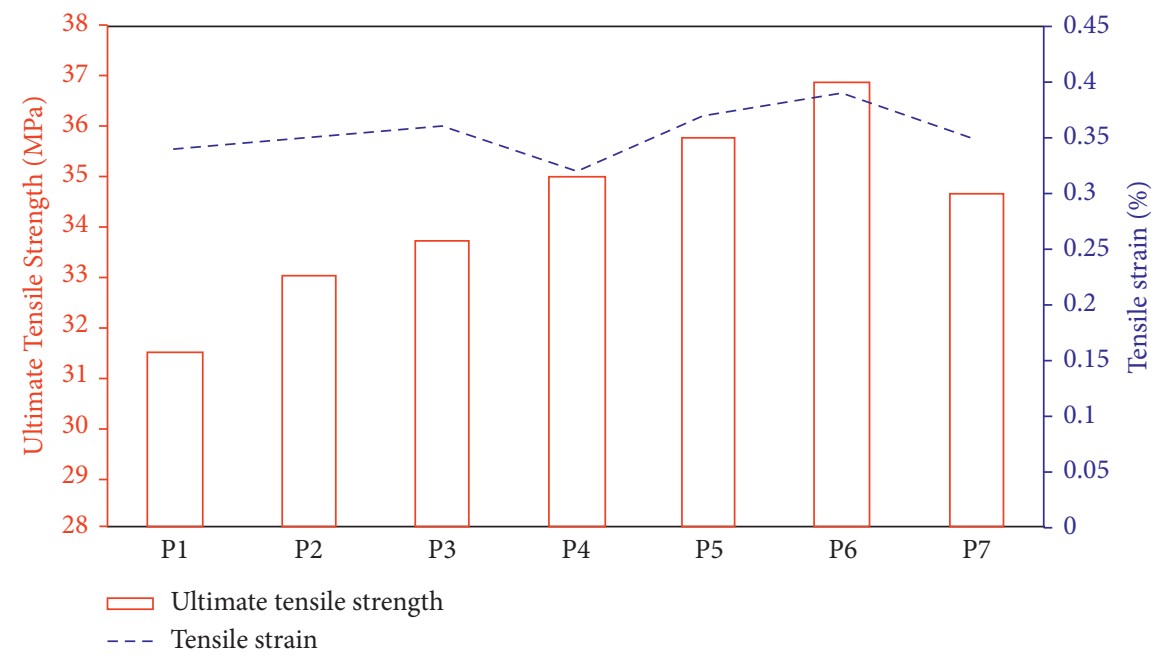

FIGURE 9: Ultimate tensile strength and strain analysis of composites.

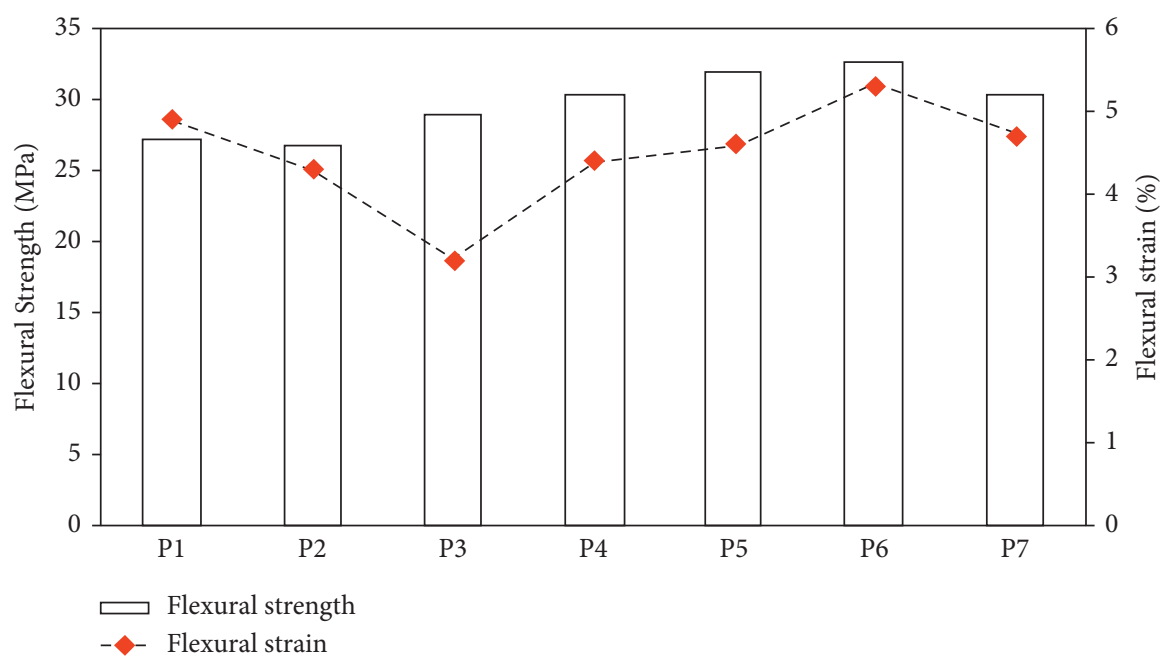

FIGURE 10: Variations on flexural strength and strain of nanosilica particles filled hybrid composites.

The plot observed that P6 composites have the highest hardness, 56\% better than pure PLA composites (P1 composites). However, the hardness of a composite depends on the homogenous distribution of the reinforced particles and fibre into the matrix. Due to the increasing hardness of this composite, the silica content and water hyacinth fibres are increased by $6 \mathrm{wt} \%$, but the loading of the particles increases slightly and gradually. The increase of the hardness value at lower particles charging can be attributed to the homogenous distribution of silica particles and water hyacinth fibre within the matrix, with a depreciation of the vacuums and a stronger interfacial adhesion between the matrix and the particles. It is worth noting that while silica has reduced the composition's tensile strength, it has increased the PLA matrix's hardness. The loading conditions are different. The low interfacial adhesion between both the tensile cargo conditions tends to cause the silica particles to debond from the PLA matrix. In the case of a hardness test, the composite is loaded vertically and downwards. This causes silica particles to be firmly pressed into the matrix. The pressure action causes a smooth transfer, although their interfacial adhesion has been poor, of the load from the matrix to the silica and water hyacinth. All of these lead to better composite hardness.

4.3. Water Absorption Properties. The durability of the water hyacinth fibre reinforced nanosilica particles filled PLA matrix biocomposites can be predicted through the water absorption tests. The weight of each specimen was measured before this test. Weight measured composite specimens are then immersed in normal water for 72 hours (three days). After this duration, the immersed specimens are taken away from the water container for the weight measuring purpose. Based on the weight of the specimen after the test, the percentage of water absorption has been calculated. The water absorption test results are illustrated in Figure 13 for all composite specimens. 


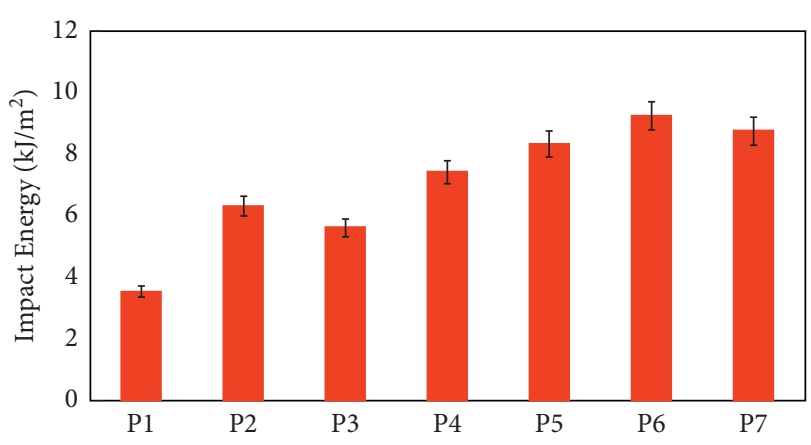

FIGURE 11: The impact energy of nanosilica particles filled hybrid composites.

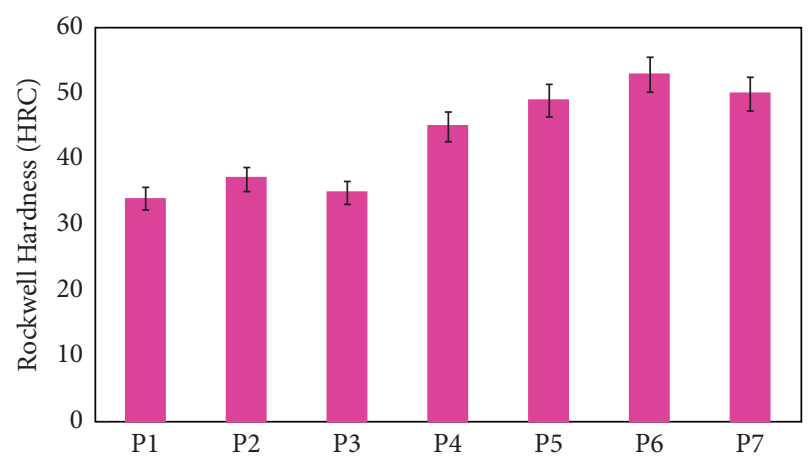

Figure 12: Rockwell hardness (HRC) values of the pure PLA and hybrid composite samples.

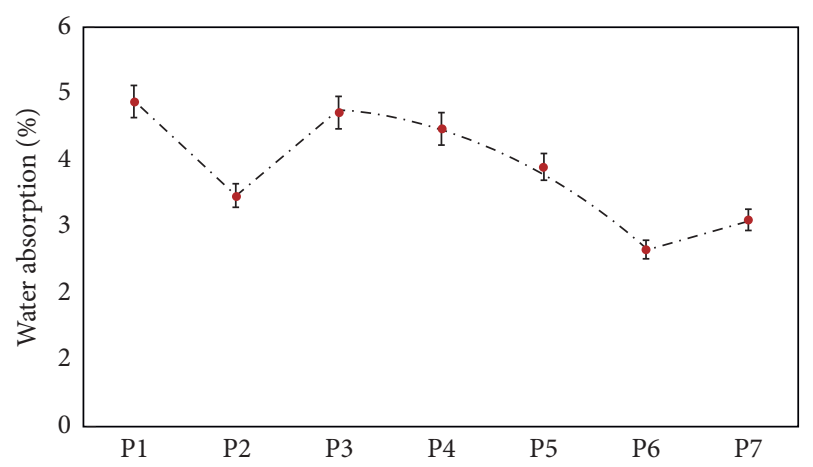

FIgURE 13: Water absorption test results of the composite specimens.

The percentage of water absorption has been calculated for all composites (P1 to P7 composite specimens) with a magnitude of $4.89,3.48,4.73,4.51,3.91,2.67$, and $3.12 \%$, respectively. The maximum weight gained by the composite specimens after the water absorption test was found in pure PLA composites (P1 composites). The minimum weight gained by the composite specimens after the water absorption test was found in $6 \%$ nanosilica particles filled composites (P6 composites). The percentage of the water absorption has found a very lesser amount at $6 \%$ nanosilica particles weight percentage added to the composites. The maximum percentage of water absorption (4.89\%) has been found at composites without the nanosilica particles and water hyacinth particles. The water absorption of the specimens has significantly reduced to increasing weight percentages of the nanosilica particles, which are added to the water hyacinth fibre PLA composites. Superior water absorption behaviour, due to removal of lignin, cellulose, and hemicellulose in the water hyacinth fibre, has been found in $14 \mathrm{wt} \%$ water hyacinth fibre enhanced composite specimens, and spaces may be made in the water hyacinth fibre molecules. The addition of limited filler content ( $6 \mathrm{wt}$ percent), i.e., nanosilica particles in water hyacinth fibre voids, has been filled in and enhances the good quantity of water interface between water hyacinth fluid and PLA matrix.

\section{Conclusions}

Mechanical tests were carried out on the water hyacinth fibre which enhanced PLA matrix composites, nanosilica particles, and water hyacinth particulate matter. After the standard tests, the following observations are noted.

(1) The water hyacinth fibre enhanced epoxy composite is successfully produced by loading nanosilica particles with various proportions of hyacinth fibre particles.

(2) Tests such as tensile, bending, impact, hardness, and water absorption are conducted in different proportions. Based on tests, nanosilica particles and water hyacinth particles increase the specimens strengths considerably.

(3) The combinations of the two particles (6\% nanosilica and $14 \%$ water hyacinth) nevertheless demonstrated their extraordinary efficiency in every test.

(4) It is suggested that both water hyacinth fibre and nanosilica particles reinforced PLA hybrid composites can be used as an alternate material for materials reinforced with natural fibre.

(5) Moreover, the most valuable aspect of this research is that water hyacinth, which is considered a waste and environmental pollutant, makes products that may replace high-cost glass fibre-based composites and help grow a healthier aquatic environment for the fishes and other aquatic plants.

\section{Data Availability}

The data used to support the findings of this study are included within the article.

\section{Conflicts of Interest}

The authors declare that there are no conflicts of interest regarding the publication of this article.

\section{Acknowledgments}

The authors appreciate the support from Seenu Atoll School, Maldives. The authors thank Bharath Institute of Higher 
Education and Research, Chennai, and this project was supported by Researchers Supporting Project number (RSP2021/257), King Saud University, Riyadh, Saudi Arabia.

\section{References}

[1] T. Ahmed, M. Shahid, F. Azeem et al., "Biodegradation of plastics: current scenario and future prospects for environmental safety," Environmental Science and Pollution Research, vol. 25, no. 8, pp. 7287-7298, 2018.

[2] V. Mohanavel, S. Suresh Kumar, J. Vairamuthu, P. Ganeshan, and B. NagarajaGanesh, "Influence of stacking sequence and fiber content on the mechanical properties of natural and synthetic fibers reinforced penta-layered hybrid composites," Journal of Natural Fibers, vol. 2021, Article ID 1875368, 13 pages, 2021.

[3] M. Asrofi, H. Abral, A. Kasim, and A. Pratoto, "XRD and FTIR studies of nanocrystalline cellulose from water hyacinth (eichornia crassipes) fiber," Journal of Metastable and Nanocrystalline Materials, vol. 29, pp. 9-16, 2017.

[4] H. Abral, M. H. Dalimunthe, J. Hartono et al., "Characterization of tapioca starch biopolymer composites reinforced with micro scale water hyacinth fibers," Starch - Stärke, vol. 70, no. 7-8, p. 1700287, Article ID 1700287, 2018.

[5] A. Komuraiah, N. S. Kumar, and B. D. Prasad, "Chemical composition of natural fibers and its influence on their mechanical properties," Mechanics of Composite Materials, vol. 50, no. 3, pp. 359-376, 2014.

[6] P. K. Panda, J.-M. Yang, Y.-H. Chang, and W.-W. Su, "Modification of different molecular weights of chitosan by p-Coumaric acid: preparation, characterization and effect of molecular weight on its water solubility and antioxidant property," International Journal of Biological Macromolecules, vol. 136, pp. 661-667, 2019.

[7] P. K. Panda, J. M. Yang, and Y. H Chang, "Water-induced shape memory behavior of poly (vinyl alcohol) and p-coumaric acid-modified water-soluble chitosan blended membrane," Carbohydrate Polymers, vol. 257, p. 117633, Article ID 117633, 2021.

[8] S. Karimi, A. Abdulkhani, P. M. Tahir, and A. Dufresne, "Effect of cellulosic fiber scale on linear and non-linear mechanical performance of starch-based composites," International Journal of Biological Macromolecules, vol. 91, pp. 1040-1044, 2016.

[9] M. Asrofi, H. Abral, Y. K. Putra, S. Sapuan, and H.-J. Kim, "Effect of duration of sonication during gelatinization on properties of tapioca starch water hyacinth fiber biocomposite," International Journal of Biological Macromolecules, vol. 108, pp. 167-176, 2018.

[10] H. Abral, G. J. Putra, M. Asrofi, J.-W. Park, and H.-J. Kim, "Effect of vibration duration of high ultrasound applied to bio-composite while gelatinized on its properties," Ultrasonics Sonochemistry, vol. 40, pp. 697-702, 2018.

[11] M. Asrofi, H. Abral, A. Kasim, and A. Pratoto, "Characterization of the microfibrillated cellulose from water hyacinth pulp after alkali treatment and wet blending," IOP Conference Series: Materials Science and Engineering, vol. 204, Article ID 012018, 2017.

[12] S. Wahono, A. Irwan, E. Syafri, and M. Asrofi, "Preparation and characterization of ramie cellulose nanofibers/CaCO3 unsaturated polyester resin composites," ARPN J. Eng. Appl. Sci.vol. 13, no. 2, pp. 746-751, 2018.

[13] E. Syafri, H. Abral, and A. Asben, "Effect of precipitated calcium carbonate on physical, mechanical and thermal properties of cassava starch bioplastic composites," International Journal of Advanced Science, Engineering and Information Technology, vol. 7, no. 5, pp. 1950-1956, 2017.

[14] M. J. Fabra, M. Martínez-Sanz, L. G. Gómez-Mascaraque, R. Gavara, and A. López-Rubio, "Structural and physicochemical characterization of thermoplastic corn starch films containing microalgae," Carbohydrate Polymers, vol. 186, pp. 184-191, 2018.

[15] A. M. Salaberria, J. Labidi, and S. C. M. Fernandes, "Chitin nanocrystals and nanofibers as nano-sized fillers into thermoplastic starch-based biocomposites processed by meltmixing," Chemical Engineering Journal, vol. 256, pp. 356-364, 2014.

[16] H. P. S. Abdul Khalil, Y. Y. Tye, C. K. Saurabh et al., "Biodegradable polymer films from seaweed polysaccharides: a review on cellulose as a reinforcement material," Express Polymer Letters, vol. 11, no. 4, pp. 244-265, 2017.

[17] G. C. O. Isaac and O. Igwe, "Studies on properties of egg shell and fish bone powder filled polypropylene," American Journal of Polymer Science, vol. 2, no. 4, pp. 56-61, 2012.

[18] Y. N. P. Njogu, R. Kinyua, and P. Muthoni, "Biogas production using water hyacinth (eicchornia crassipes) for electricity generation in Kenya," Energy and Power Engineering, vol. 07, no. 5, pp. 209-216, 2015.

[19] T. D. Pham, C. M. Vu, and H. J. Choi, "Enhanced fracture toughness and mechanical properties of epoxy resin with rice husk-based nano-silica," Polymer Science - Series A, vol. 59, no. 3, pp. 437-444, 2017.

[20] M. Al Amin and M. Rafiquzzaman, "Charpy impact behavior of Water Hyacinth fiber based polymer composite," J. Mater. Sci. Manuf. Technol.vol. 2, no. 2, pp. 1-13, 2018, https://www. researchgate.net/publication/320700216\%0ACharpy.

[21] M. Megahed, A. Megahed, and M. Agwa, "The influence of incorporation of silica and carbon nanoparticles on the mechanical properties of hybrid glass fiber reinforced epoxy," Journal of Industrial Textiles, vol. 49, no. 2, pp. 181-199, 2019.

[22] O. S. Akintayo, "Mechanical properties of epoxy matrix composites reinforced with green silica particles," Annals of the Faculty of Engineering Hunedoara, vol. 15, no. 4, pp. 167-174, 2017.

[23] K. L. Kuzmin, I. A. Timoshkin, S. I. Gutnikov, E. S. Zhukovskaya, Y. V. Lipatov, and B. I. Lazoryak, "Effect of silane/nano-silica on the mechanical properties of basalt fiber reinforced epoxy composites," Composite Interfaces, vol. 24, no. 1, pp. 13-34, 2017.

[24] C. N. A. Jaafar, M. A. M. Rizal, and I. Zainol, "Effect of kenaf alkalization treatment on morphological and mechanical properties of epoxy/silica/kenaf composite," International Journal of Engineering \& Technology, vol. 7, no. 4, pp. 258263, 2018.

[25] A. A. Hasibuan, R. Yuniati, and W. Wardhana, "The growth rate and chlorophyll content of water hyacinth under different type of water sources," IOP Conference Series: Materials Science and Engineering, vol. 902, Article ID 012064, 2020.

[26] O. P. Iio, M. D. Simatele, S. L. Nkomo, N. M. Mkhize, and N. G. Prabhu, "The benefits of water hyacinth (Eichhornia crassipes) for southern africa: a review," Sustainability, vol. 12, p. $9222,2020$. 